\title{
Adsorption Performance and Evaluation of Activated Carbon from Coconut Shell for the Removal of Chlorinated Phenols in Aqueous Medium
}

\author{
Collin G JOSEPH ${ }^{1}$ *, SM ANISUZZAMAN ${ }^{2}$, Sariah ABANG ${ }^{2}$, Baba MUSTA ${ }^{1}$, \\ Kye Shane QUEK ${ }^{1}$, Xin Lin WONG ${ }^{1}$
}

\author{
${ }^{1}$ Water Research Unit, Faculty of Science \& Natural Resource, Universiti Malaysia Sabah, 88400 Kota Kinabalu, Sabah, \\ Malaysia \\ ${ }^{2}$ Chemical Engineering, Faculty of Engineering, Universiti Malaysia Sabah, 88400 Kota Kinabalu, Sabah, Malaysia \\ crossref http://dx.doi.org/10.5755/j01.ms.23.4.16221
}

Received 09 September 2016; accepted 12 February 2017

\begin{abstract}
In this study, the removal of 2,4-dichlorophenol (2,4-DCP) from aqueous solutions was performed using coconut shell activated carbon prepared by a two-stage self-generated atmosphere method. Coconut shell was first semi-carbonized at $300{ }^{\circ} \mathrm{C}$ for an hour followed by chemical activation with zinc chloride $\left(\mathrm{ZnCl}_{2}\right)$ as activating agent at $500{ }^{\circ} \mathrm{C}$ for $2 \mathrm{~h}$. The effect of impregnation ratio on the physical and chemical properties of activated carbons (ACs) was studied. The morphology and surface chemistry of the prepared carbons were characterized using Scanning Electron Microscope (SEM) and Fourier Transform Infrared spectroscopy (FTIR) respectively. The percentage of yield for the prepared AC was found to be in the range of $26.40-38.82 \%$. AC registered the highest adsorption capacity and was used in subsequent batch adsorption studies consisting of parameters such as initial concentration, adsorbent dosage and solution $\mathrm{pH}$. The maximum surface area of the best produced AC was recorded as $1482 \mathrm{~m}^{2} \mathrm{~g}^{-1}$. The adsorption capacity was found to increase in proportional to the initial concentration and adsorbent dosage, while acidic solution $\mathrm{pH}$ was more favourable for the adsorption of 2,4-DCP by the prepared AC. The equilibrium time for the adsorption of $20 \mathrm{mg} \mathrm{L}^{-1}$ of 2,4-DCP on $0.5 \mathrm{~g}$ of AC was achieved in $180 \mathrm{~min}$. Adsorption isotherms such as Langmuir, Freundlich and Temkin isotherm models were employed to examine the experimental isotherms while the reaction kinetic data was analysed using pseudo-first-order, pseudo-second-order and intraparticle diffusion model. The 2,4-DCP adsorption results fitted best in the Freundlich isotherm as indicated by the high correlation coefficient value $(\mathrm{R} 2>0.9949)$ while the adsorption kinetic fitted to the pseudo second-order model $(\mathrm{R} 2>0.9621)$.

Keywords: activated carbon, two stage self-generated atmosphere, 2,4-dichlorophenol, coconut shell, adsorption.
\end{abstract}

\section{INTRODUCTION}

Chlorophenols are among the most toxic pollutants found in industrial wastewater and can cause the biomagnification toxicity to aquatic flora and fauna via the food chain link $[1,2]$. Owing to their toxicity and adverse effect upon human and biota, the U.S. Environmental Protection Agency (EPA) and the European Union (EU) have classified these class of chemicals as priority pollutants [3]. Hence, it is crucial to remove these organic pollutants from the environment. Many methods have been studied for the removal of chlorinated phenols from aqueous solution, for instance, microbial degradation, chemical oxidation, sonophotochemical, adsorption, ultrasonic degradation, enzymatic polymerization and photocatalytic degradation using $\mathrm{TiO}_{2}$. Among these methods, adsorption offers an efficient and economically feasible technology in wastewater treatment. Adsorption with activated carbon (AC) has been cited by the US Environmental Protection Agency as one of the best available environmental control technologies [4]. Commercially available AC, however, is expensive and this leads to a vast research in finding for cheap and efficient materials. Agricultural by-products have been widely used as the raw materials for the production of AC

\footnotetext{
* Corresponding author. Tel.: +6 088 320000×2117; fax: +6 088435324 . E-mail address: collin@ums.edu.my (C.G. Joseph)
}

because they are abundant, renewable and inexpensive. Among the numerous agricultural wastes, coconut shell is one of the most employed biomass for industrial purposes not only due to its large availability but also because of its high carbon content and mechanical strength that make it an excellent precursor for AC production [5-9].

AC can be prepared via two methods: physical activation and chemical activation. Physical activation is a two-stage process whereby a carbonaceous material is first carbonized followed by activation of the resulting char at elevated temperature in the presence of suitable oxidizing gases such as carbon dioxide or steam. Chemical activation, on the other hand, is a single stage method which involves the impregnation of the starting material with an activating agent and this process can be conducted at lower temperature than physical activation. There are many chemicals that are frequently used as the activating agent such as phosphoric acid $\left(\mathrm{H}_{3} \mathrm{PO}_{4}\right)$, zinc chloride $\left(\mathrm{ZnCl}_{2}\right)$, and some alkalis compound include potassium hydroxide $(\mathrm{KOH})$, potassium carbonate $\left(\mathrm{K}_{2} \mathrm{CO}_{3}\right)$, as well as sodium carbonate $\left(\mathrm{Na}_{2} \mathrm{CO}_{3}\right)$ [10-12]. However, some alkalis compound such as $\mathrm{KOH}$ are hazardous, expensive and corrosive [13].

Chemical activation offers several advantages over physical activation which include low activation time, higher yields and better porous structure but it involves a complex recovery and recycle of activating agent which leads to an environment pollution [14]. Physical activation, 
especially steam activation, conforms to the need for cleaner production but it requires a much longer time. Hence, the objective of this study was to evaluate the feasibility of 2 stages activated coconut shell-based carbon for the removal of 2,4-dichlorophenol (2,4-DCP) from aqueous solution. Preparation of AC was done with a few preselected impregnation ratio and activation temperature by a 2 stages self-generated atmosphere method [15]. Coconut shell first underwent semi-carbonization at $300{ }^{\circ} \mathrm{C}$ for $1 \mathrm{~h}$ followed by chemical activation at $500{ }^{\circ} \mathrm{C}$ for $2 \mathrm{~h}$ with $\mathrm{ZnCl}_{2}$ as activating agent.

\section{EXPERIMENTAL}

\subsection{Preparation of $\mathrm{AC}$}

Coconut shells were obtained from a market in Kota Kinabalu, Sabah, Malaysia. Prior to use, the precursors were first ground and cut into a particle size in the range of $1-2 \mathrm{~cm}$, then washed carefully with distilled water to remove dirt and dried at $110^{\circ} \mathrm{C}$ for $24 \mathrm{~h}$ to remove moisture. The dried sample was then semi-carbonization in a muffle furnace at $300{ }^{\circ} \mathrm{C}$ for $1 \mathrm{~h} \mathrm{[16]}$. The chars obtained from pyrolysis were impregnated with $\mathrm{ZnCl}_{2}$ solution. The impregnation ratio was varied from $1: 1$ to $5: 1$ according to the $\mathrm{ZnCl}_{2}$ :chars ratio $(\mathrm{w} / \mathrm{w})$. The activating agent and the semi-carbonized carbon were homogeneously mixed at $85^{\circ} \mathrm{C}$ until the solution was completely dried [17]. The resulted samples were activated under self-generated atmosphere at $500{ }^{\circ} \mathrm{C}$ for $2 \mathrm{~h}$ [18]. After cooling, the activated samples were repetitively washed with $0.01 \mathrm{M}$ hydrochloric acid $(\mathrm{HCl})$ solution to remove the excess activating agent followed by hot distilled water until a neutral $\mathrm{pH}$ was reached [19]. The samples were then dried in an oven at $110{ }^{\circ} \mathrm{C}$ for $24 \mathrm{~h} \mathrm{[20].}$

\subsection{Characterization of $\mathrm{AC}$}

The prepared ACs were characterized for percentage of yield, moisture and ash content, $\mathrm{pH}$ value and chlorinated phenols adsorption capacity from aqueous solution. The yield of the AC was calculated as the ratio of the weight of the resultant $\mathrm{AC}$ to that of the original coconut shell with both weights on a dry basis. The moisture content, ash content and $\mathrm{pH}$ value were evaluated using ASTM standard methods (ASTM D2867-04, ASTM D2866-94, ASTM D 3838-80). Fourier transform infrared spectroscopy (FTIR) analysis was applied to the AC for surface functional groups identification. Surface physical morphologies of the activated carbons were studied by scanning electron microscopy (SEM) (JEOL JSM5610LV). The specific surface area and the pore-size distribution were determined using the Brunauer, Emmet and Teller (BET) and Barret, Joyner and Halenda (BJH) methods, respectively. The BET surface area and pore size distribution were determined from nitrogen isotherm at 77.3 K using Quanta chrome autosorb automated gas sorption instrument [21].

\subsection{Batch adsorption studies}

In this study, to determine the adsorption capacity of AC from aqueous solution, 2,4-DCP was selected as a representative of phenolic pollutants. The effect of initial concentration, adsorbent dosage and $\mathrm{pH}$ were studied by carrying out adsorption studies in a batch mode. A series of $250 \mathrm{~mL}$ Erlenmeyer conical flasks containing $600 \mathrm{~mL}$ of 2,4-DCP solution of concentration varied from $5 \mathrm{mg} \mathrm{L}^{-1}$ to $20 \mathrm{mg} \mathrm{L}^{-1}$ were mixed with $0.5 \mathrm{~g}$ of adsorbents and agitated intermittently for $3 \mathrm{~h}$. After that, the solution was filtered and the 2,4-DCP concentration was determined using the UV/Vis spectrophotometer at $285 \mathrm{~nm}$ [22]. The equilibrium adsorption uptake, $q_{e}\left(\mathrm{mg} \mathrm{g}^{-1}\right)$ was calculated using the following relationship:

$q_{\mathrm{e}}=\frac{\left(C_{0}-C_{\mathrm{e}}\right)}{W}$

where $c_{0}$ is the initial adsorbate concentration $\left(\mathrm{mg} \mathrm{L}^{-1}\right), c_{\mathrm{e}}$ is the equilibrium adsorbate concentration $\left(\mathrm{mg} \mathrm{L}^{-1}\right), V$ is the volume of the solution (L) and $W$ is the mass of the adsorbent $(\mathrm{g})$.

The effect of adsorbent dosage was studied by agitating $600 \mathrm{~mL}$ of $20 \mathrm{mg} \mathrm{L}^{-1} 2,4-\mathrm{DCP}$ solution with different adsorbent doses $(0.1,0.3$, and $0.5 \mathrm{~g}$ ). Effect of solution $\mathrm{pH}$ on adsorption capacity was examined by altering the $\mathrm{pH}$ of $600 \mathrm{~mL}$ of $20 \mathrm{mg} \mathrm{L}^{-1} 2,4$-DCP to $\mathrm{pH} 3,7$ and 9 and mixing each of them with $0.5 \mathrm{~g}$ of AC sample. The $\mathrm{pH}$ of the solution was adjusted using $0.1 \mathrm{M} \mathrm{HCl}$ and $0.1 \mathrm{M} \mathrm{NaOH}$ [23]. The mixture was stirred for $180 \mathrm{~min}$ and filtered. The adsorption capacity of 2,4-DCP was then determined by UV/Vis spectrophotometer. The same procedure was applied for batch kinetic studies but the solution was extracted out every $10 \mathrm{~min}$ for UV/Vis spectroscopy analysis. Langmuir, Freundlich and Temkin isotherm models were used to examine the experimental isotherms while kinetic data was analysed using pseudofirst-order, pseudo-second-order and intraparticle diffusion model.

\section{RESULTS AND DISCUSSION}

\subsection{Carbon properties}

The prepared ACs were characterized by selected physical and chemical properties. The yields, $\mathrm{pH}$, moisture and ash content of ACs are shown in Table 1. The result showed a significant effect of impregnation ratio on AC yields. The yield of carbon increased from $26.40 \%$ to $38.82 \%$ as the ratio increase from $1: 1$ to $1: 3$. This is because $\mathrm{ZnCl}_{2}$, promotes the decomposition of carbonaceous material, inhibits the formation of tar and allowing the fixation of more carbon in the matrix. This eventually led to an increase in the carbon yields [24]. However, the yield started to decrease from ratio 1:3 to 1:5. This loss of weight is probably due to the large evolution of volatile matters as a result of intensifying dehydration. The moisture content obtained from the AC was in the range of $3.08-4.36 \%$. The overall moisture content fluctuated and did not show a constant trend. This suggests that there was no significant effect of impregnation ratio on the moisture content. As shown in Table 1, the ash content obtained from the prepared sample was relatively low which was less than $3 \%$ in an overall pattern. This result agrees with the study of Ahmedna and co-workers [25], which revealed that the low ash content of shell based carbons is due to the low inherent mineral 
content of shells. The $\mathrm{pH}$ value for the samples was in a range of 5.50 to 5.90 , indicating that the surface of the activated carbon contained acidic functional groups.

Table 1. Percentage yield, moisture content, ash content and $\mathrm{pH}$ of sample

\begin{tabular}{|c|c|c|c|c|}
\hline Sample & $\begin{array}{c}\text { Impregnation } \\
\text { ratio }\end{array}$ & $\begin{array}{c}\text { Product } \\
\text { yield, \% }\end{array}$ & $\begin{array}{c}\text { Moisture } \\
\text { content, \% }\end{array}$ & $\begin{array}{c}\text { Ash } \\
\text { content, \% }\end{array}$ \\
\hline AC1 & $1: 1$ & 26.40 & 4.36 & 2.91 \\
\hline AC2 & $2: 1$ & 36.76 & 3.67 & 0.41 \\
\hline AC3 & $3: 1$ & 38.82 & 3.73 & 1.24 \\
\hline AC4 & $4: 1$ & 36.38 & 3.27 & 0.82 \\
\hline AC5 & $5: 1$ & 32.28 & 3.08 & 2.26 \\
\hline
\end{tabular}

\subsection{Morphology studies}

Scanning electron microscopy (SEM) was used to observe the surface morphology of coconut shell and prepared activated carbons. Fig. $1 \mathrm{a}-\mathrm{f}$ shows the SEM images of the raw coconut shell and its derived ACs in $1000 \mathrm{x}$ magnification. It is clear that there were significant differences between the surface topography of raw material and that of the prepared ACs. As shown Fig. 1 a, the surface of the coconut shell was smooth with few cracks or voids. The ACs, however, are full of cavities and pores with different sizes and shapes (Fig. $1 \mathrm{~b}-\mathrm{f}$ ). These pores resulted from the release of volatile components as well as the evaporation of $\mathrm{ZnCl}_{2}$ from spaces that it previously occupied. The sizes and shapes of pores depend on the impregnation ratios. $\mathrm{ZnCl}_{2}$ activation caused the lateral bonds in the cellulosic molecules to break, leading to an increase of inter- and intra-voids. This phenomenon is apparent in AC2, Fig. $1 \mathrm{c}$. As the impregnation ratio increases, mesopores are formed resulted from pore widening. It can be seen in Fig. $1 \mathrm{e}$, some of the pores in AC4 started to break. This implies that pore widening is the dominant mechanism at high impregnation ratio.

\subsection{FTIR analysis}

The chemical reactivity of functional groups present at the surface of an AC contributes significantly on the adsorption capacity. Hence, understanding of the surface functional group will give insight to the adsorption capability of the prepared ACs [26]. Fig. 2 illustrates the FTIR spectrum for raw coconut shells and Fig. 3 shows the FTIR spectra of the prepared ACs. As seen in Fig. 2, the FTIR spectrum of the raw coconut shell shows various surface functional groups.

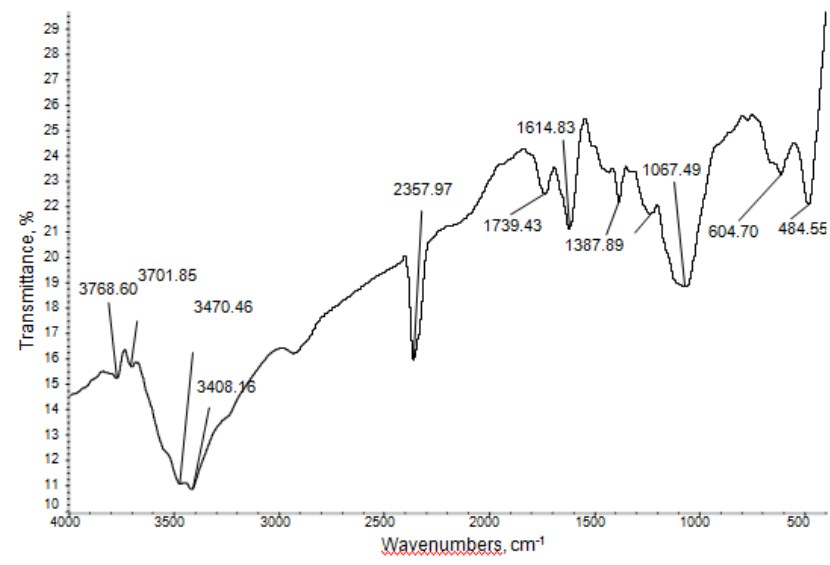

Fig 2. FTIR spectra for the raw coconut shell

The broad band at $3406.16 \mathrm{~cm}^{-1}$ is assigned to the hydroxyl groups $(-\mathrm{OH})$. The band at around $2900 \mathrm{~cm}^{-1}$ is attributed to the $\mathrm{C}-\mathrm{H}$ stretching while the band appearing at $1739.43 \mathrm{~cm}^{-1}$ is assigned to the carbonyl groups $(\mathrm{C}=\mathrm{O})$. The band found at $1387.89 \mathrm{~cm}^{-1}$ and $1614.83 \mathrm{~cm}^{-1}$ showed the presence of aromatic rings due to $\mathrm{C}=\mathrm{C}$ stretch. The band at $1236.59 \mathrm{~cm}^{-1}$ and a relatively intense band at $1067.49 \mathrm{~cm}^{-1}$ may be attributed to the $\mathrm{C}-\mathrm{O}$ stretching in ethers, alcohols or phenols.

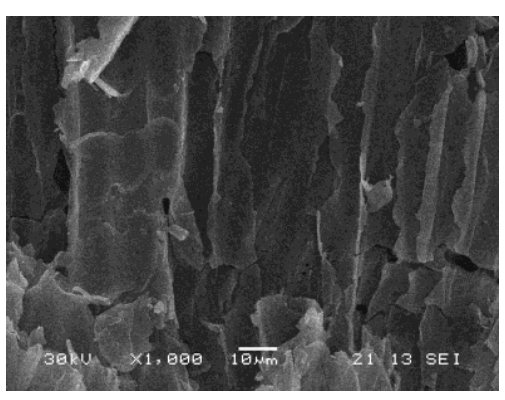

a

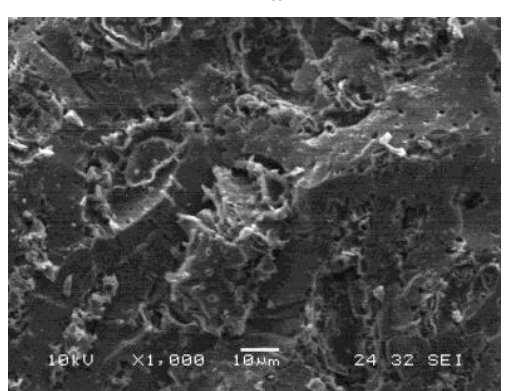

d

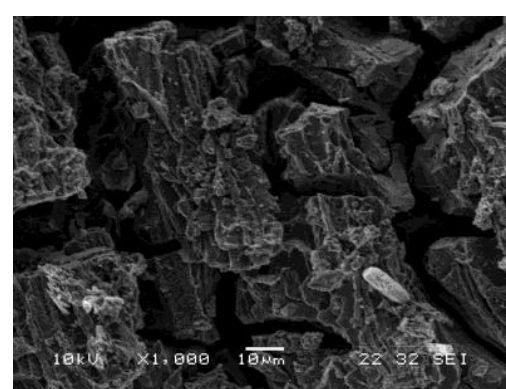

b

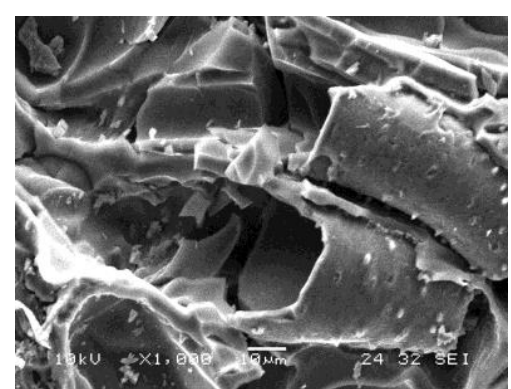

e

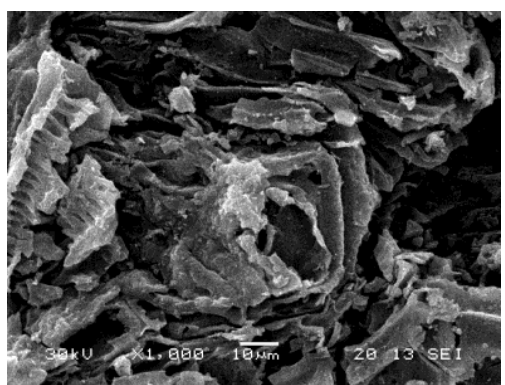

$\mathrm{c}$

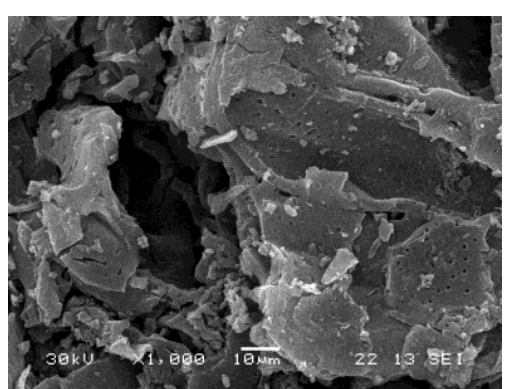

f

Fig. 1. SEM images: $a-r a w ~ m a t e r i a l ; ~ b-A C 1 ; c-A C 2 ; d-A C 3 ; e-A C 4 ; f-A C 5$ 
The presence of hydroxyl groups, carbonyl groups, ethers or phenols, and aromatic compounds proves the lignocellulosic structure of coconut shell [27]. The FTIR spectrum of activated samples given in Fig. 3 shows a decrease of bands when compares with the raw material spectrum. This indicates a decrease of functional groups in the raw material. It can be observed that bands at around $3400 \mathrm{~cm}^{-1}, 1739 \mathrm{~cm}^{-1}, 1236 \mathrm{~cm}^{-1}$ and $1067 \mathrm{~cm}^{-1}$, which corresponds to the presence of $-\mathrm{OH}, \mathrm{C}=\mathrm{O}$, and aromatic $\mathrm{C}=\mathrm{C}$ stretch have disappeared in the activated carbons spectrum. These changes implied that there was a break of chemical bonds during the carbonization and activation process. An intense peak which appeared at approximately $2357 \mathrm{~cm}^{-1}$ in both spectra can be assigned to $\mathrm{C} \equiv \mathrm{C}$ stretching in alkyne groups.

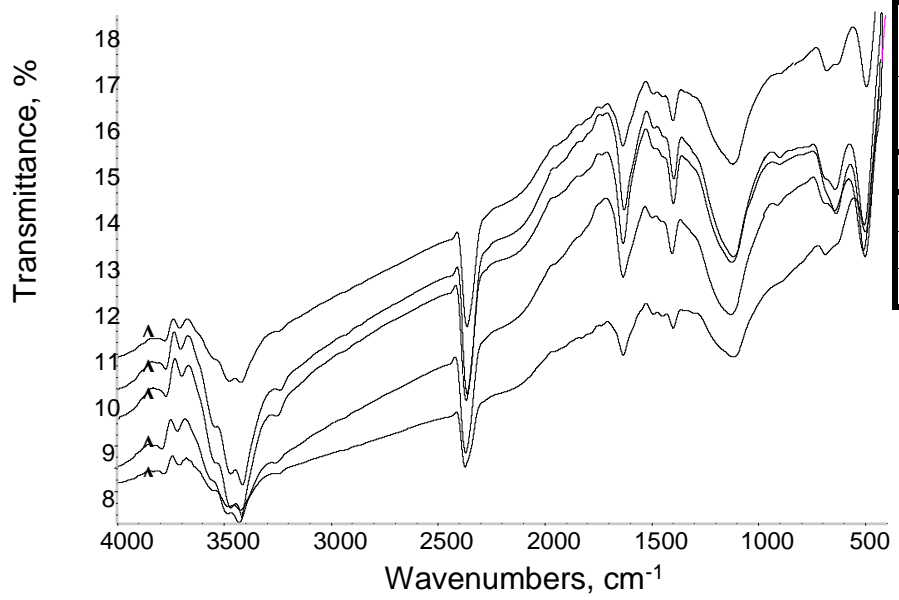

Fig. 3. FTIR spectra for prepared ACs

\subsection{Specific surface area and pore-distribution}

AC2 was selected for surface area and pore distribution analysis. The maximum Langmuir surface area of sample AC2 was found to be $1482 \mathrm{~m}^{2} \mathrm{~g}^{-1}$ and the average pore diameter of $21.88 \AA$ which is comparable with the findings of other researchers. Table 2 represents the porous and surface characteristics of AC2 [14, 19, 26, $28-31]$.

Fig.4 shows the isotherms from $\mathrm{N}_{2}$-sorption measurements of the AC4 which contains specific information on the porosity of the particles at the temperature of liquid nitrogen.

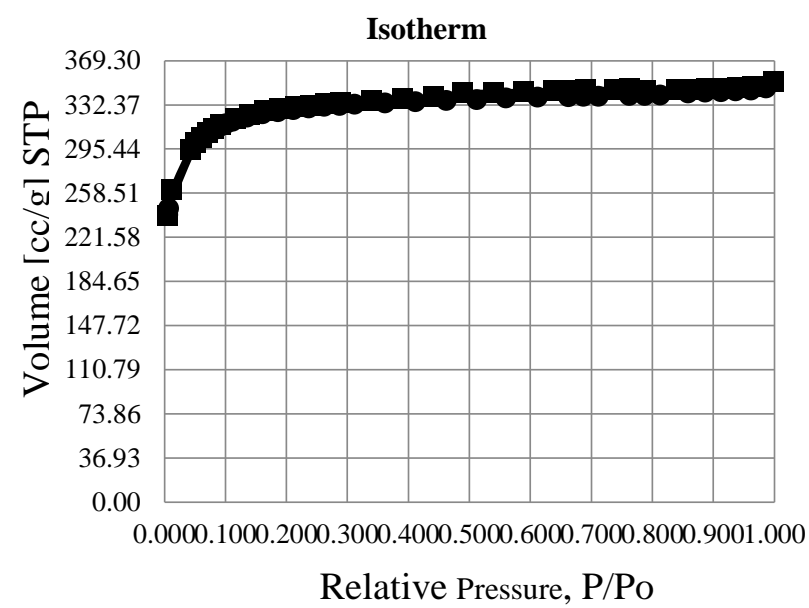

Fig. 4. The $\mathrm{N}_{2}$ adsorption-desorption isotherms of the AC2
In Fig. 4, Type I isotherm with no hysteresis loop was observed. This isotherm corroborates with the Langmuir isotherm model which indicates monolayer coverage with chemisorption adsorption properties due to the compliance with the pseudo-second-order reaction kinetics. This is a typical adsorption in microporous solids [21].

Table 2. Surface area, pore volume and pore size of AC2

\begin{tabular}{|l|l|}
\hline Surface area & $1.482 \times 10^{3}$ \\
\hline Langmuir surface area, $\mathrm{m}^{2} \mathrm{~g}^{-1}$ & $3.720 \times 10^{2}$ \\
\hline $\begin{array}{l}\text { BJH method cumulative adsorption surface area, } \\
\mathrm{m}^{2} \mathrm{~g}^{-1}\end{array}$ & $3.828 \times 10^{2}$ \\
\hline $\begin{array}{l}\text { BJH method cumulative desorption surface area, } \\
\mathrm{m}^{2} \mathrm{~g}^{-1}\end{array}$ & \\
\hline Pore volume & $0.1697 \times 10^{-}$ \\
\hline $\begin{array}{l}\text { BJH method cumulative adsorption pore volume, } \\
\mathrm{m}^{3} \mathrm{~g}^{-1}\end{array}$ & 2 \\
\hline $\begin{array}{l}\text { BJH method cumulative desorption pore volume, } \\
\mathrm{m}^{3} \mathrm{~g}^{-1}\end{array}$ & $0.1746 \times 10^{-}$ \\
\hline Pore size & 21.88 \\
\hline Average pore diameter, $\AA$ & 13.41 \\
\hline BJH method adsorption pore diameter (mode), $\AA$ \\
\hline BJH method desorption pore diameter (mode), $\AA$ & 13.26 \\
\hline
\end{tabular}

\subsection{Adsorption studies}

The adsorption capacity of the prepared ACs was evaluated by the performance of 2,4-DCP adsorption experiment. Prior to this, the prepared carbons were ground to $100-120$ mesh. The result obtained is presented in Fig. 5. It can be seen that the efficiency of sample in the removal of 2,4-DCP is largely affected by the impregnation ratio. As the impregnation ratio increases from $1: 1$ to $2: 1$, corresponding to $\mathrm{AC} 1$ and $\mathrm{AC} 2$, the adsorption capacity increases. The adsorption capacity, however, shows a gradual decrease with the further increase of impregnation ratio, which is represented by AC3, AC4 and AC5. Since the porosity of AC accounts primarily for its adsorption capacity, it can be concluded that the impregnation ratio plays a vital role in the development of porous. This finding is corroborated with the study conducted by Khalili and co-workers [24], which stated that a prescribed microporous or mesoporous AC could be produced by controlling the amount of $\mathrm{ZnCl}_{2}$ used during chemical activation. $\mathrm{ZnCl}_{2}$ activation is efficient in producing $\mathrm{AC}$ with high microporosity. The creation and widening of the micropores take place simultaneously at impregnation ratio ranging from 1 to 2 . When the impregnation ratio is greater than 2, pore widening becomes the dominant mechanism and mesopores are formed [24]. AC2, therefore, exhibits the highest adsorption capacity for 2,4-DCP. Due to its high adsorptive capacity, the following adsorption studies were done using sample AC2.

\subsection{Effect of initial concentration}

The effect of initial concentration on the adsorption capacity of AC2 for 2,4-DCP is depicted in Fig. 6. It is clear that the adsorption capacity of sample depends on the initial concentration of 2,4-DCP. The adsorption of 2,4DCP by AC2 increase as the initial 2,4-DCP concentration 
increased. This is probably due to the increase of mass transfer driving force as a result of an increase in initial concentration.

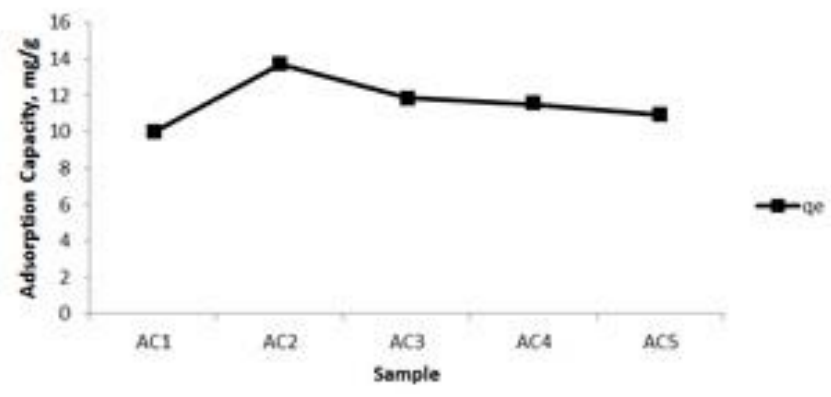

Fig. 5. Adsorption capacity of the prepared ACs for 2,4-DCP

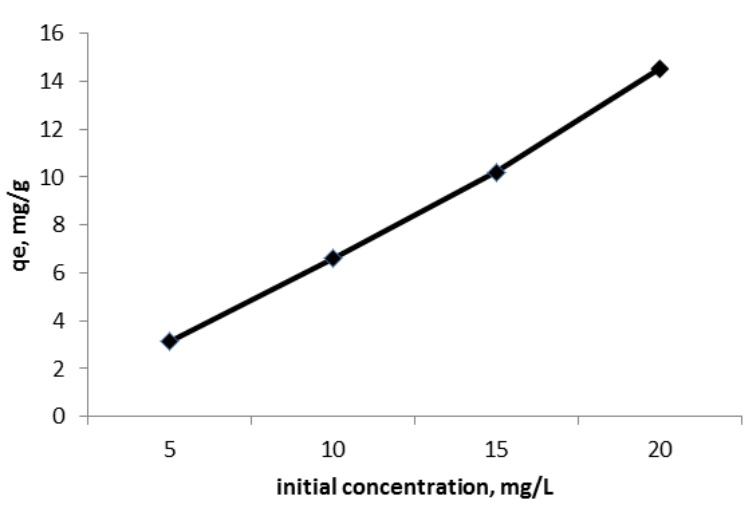

Fig. 6. Effect of initial concentration on adsorption capacity

\subsection{Effect of adsorbent dosage}

The effect of adsorbent dosage on the adsorption of 2,4-DCP was studied with $0.1,0.3$ and $0.5 \mathrm{~g}$ of $\mathrm{AC} 2$ in $20 \mathrm{mg} \mathrm{L}^{-1}$ of 2,4-DCP. Fig. 7 illustrates the adsorption capacity of sample for 2,4-DCP at the specified dosage. The adsorption increases in proportional to the increase in adsorbent dosage. This is probably due to the greater surface area and more adsorption sites arising from the increase in adsorbent dosage [32]. As shown in Fig. 7, $0.5 \mathrm{~g}$ of adsorbent dosage gave the highest adsorption capacity.

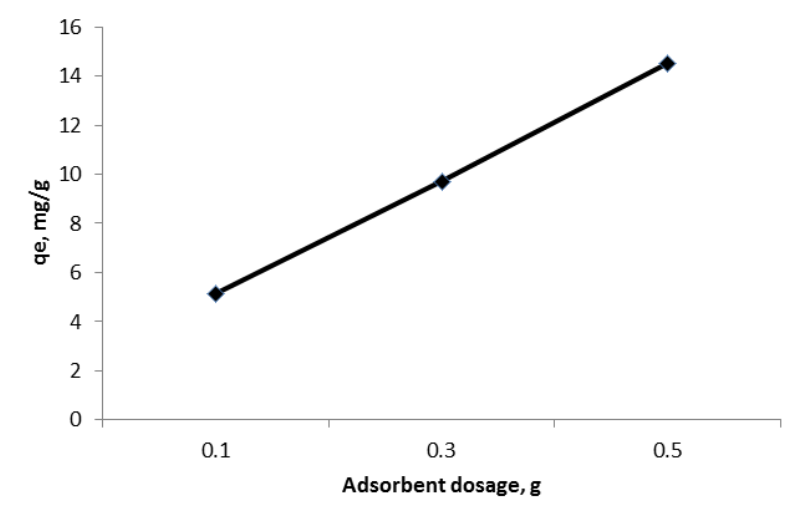

Fig. 7. Effect of adsorbent dosage on 2,4-DCP adsorption

\subsection{Effect of solution $\mathrm{pH}$}

The $\mathrm{pH}$ of the adsorption medium is an important parameter in the treatment of chlorophenols by the adsorbent as it governs the degree of ionization of acidic and basic compounds. In this study [33], the effect of solution $\mathrm{pH}$ on the adsorption of 2,4-DCP was studied by varying the initial $\mathrm{pH}$ of $20 \mathrm{mg} \mathrm{L}^{-1}$. 2,4-DCP solution to pHs 3, 7 and 9. The result was shown in Fig. 8. It can be seen from the figure that the adsorption capacity for 2,4DCP decreases as the solution $\mathrm{pH}$ increases. The highest adsorption 2,4-DCP was achieved at $\mathrm{pH} 3$, with an uptake of $14.76 \mathrm{mg} \mathrm{g}^{-1}$.

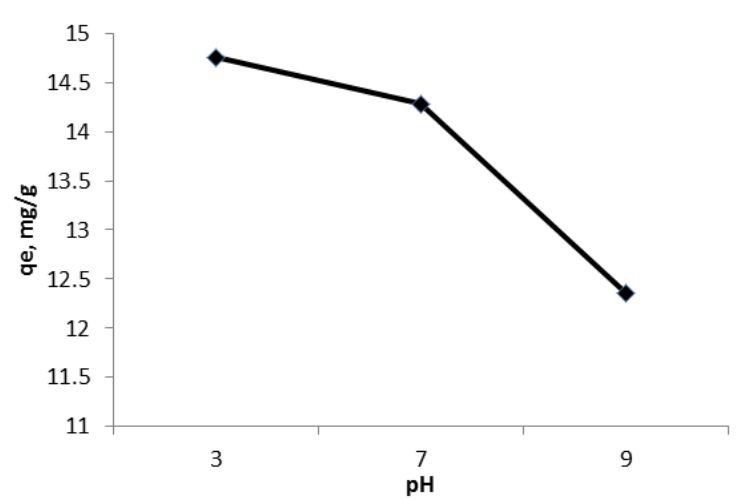

Fig. 8. Effect of solution $\mathrm{pH}$ on the adsorption of 2,4-DCP by $\mathrm{AC} 2$

\subsection{Adsorption isotherms}

Adsorption isotherm is useful in describing the distribution of adsorption molecules between the liquid phase and the solid phase when the adsorption process reaches an equilibrium state [14]. In this study, three isotherms models namely Langmuir, Freundlich and Temkin isotherm models were used to describe the relationship between the amount of 2,4-DCP adsorbed and the corresponding equilibrium concentration. The following relation represents the linearized form of Langmuir equation:

$$
\frac{C_{\mathrm{e}}}{q_{\mathrm{e}}}=\frac{1}{q_{\mathrm{m}} K_{\mathrm{L}}}+\frac{1}{q_{\mathrm{m}}} C_{\mathrm{e}}
$$

where $C_{\mathrm{e}}$ is the concentration of adsorbate in the solution at equilibrium $\left(\mathrm{mg} \mathrm{L}^{-1}\right), q_{\mathrm{e}}$ is the amount of adsorbate adsorbed $\left(\mathrm{mg} \mathrm{g}^{-1}\right), q_{\mathrm{m}}$ is the amount of adsorbate adsorbed to form monolayer coverage $\left(\mathrm{mg} \mathrm{g}^{-1}\right)$, and $K_{\mathrm{L}}$ is the Langmuir constant $\left(\mathrm{L} \mathrm{mg}^{-1}\right)$.

The linear form of the Freundlich isotherm model can be written as follow:

$$
\log q_{\mathrm{e}}=\log K_{\mathrm{f}}+\frac{1}{n} \ln C_{\mathrm{e}}
$$

where $K_{\mathrm{f}}$ and $1 / n$ are the Freundlich constants related to adsorption capacity and adsorption intensity of the sorbent respectively.

The Temkin isotherm was used in the following form:

$q_{\mathrm{e}}=B_{\mathrm{T}} \ln K_{\mathrm{T}}+B_{\mathrm{T}} \ln C_{\mathrm{e}}$,

where $K_{\mathrm{T}} \mathrm{i}$ s Temkin adsorption potential $\left(\mathrm{L} \mathrm{g} \mathrm{g}^{-1}\right), \mathrm{B}_{\mathrm{T}}$ is related to the heat of adsorption $\left(\mathrm{J} \mathrm{mol}^{-1}\right)$.

The calculated values for both Langmuir and Freundlich constants are tabulated in Table 3. The correlation coefficient, $R^{2}$ values, was used to judge the 
applicability of isotherm equation in describing the adsorption process. As can be seen in Table 3 , the $R^{2}$ values for both Langmuir and Freundlich isotherm models are higher than 0.95 , indicating that the adsorption of 2,4DCP on AC2 can be described well by both models. However, negative values are obtained for the Langmuir isotherm constant. This implies an inadequacy of the isotherm model in explaining the adsorption process, considering these constants are the sign of monolayer coverage and surface binding energy [34].

Table 3. Langmuir and Freundlich constants for the adsorption of 2,4-DCP on AC2

\begin{tabular}{|c|c|c|c|c|c|c|}
\hline \multirow{2}{*}{ Sample } & \multicolumn{3}{|c|}{ Langmuir Isotherm } & \multicolumn{3}{c|}{ Freundlich Isotherm } \\
\cline { 2 - 7 } & $K_{\mathrm{L}}$ & $q_{\mathrm{m}}$ & $R^{2}$ & $K_{\mathrm{f}}$ & $1 / n$ & $R^{2}$ \\
\hline $\mathrm{AC} 2$ & -0.045 & -26.042 & 0.967 & 1.015 & 1.260 & 0.995 \\
\hline
\end{tabular}

Thus, it can be concluded that the adsorption process does not follow the assumption on which the Langmuir approach was based. The Freundlich constants, $K_{\mathrm{f}}$ determines the sorption capacity of adsorbent. High value of $K_{\mathrm{f}}$ indicates high sorption capacity. The $K_{\mathrm{f}}$ value in this study, however, is relatively low suggests that the sample is not very effective in $2,4-\mathrm{DCP}$ sorption. The slope $1 / n$ is a measure of adsorption intensity or surface heterogeneity, generally in the range of 0 to 1 [23]. The higher the value of $1 / n$ the more intensive the adsorption process becomes. The data in this study fits well to the Freundlich model, which indicates the heterogeneity of the adsorbed surface. The intensity of adsorbate/adsorbent interaction is implied by the value of $K_{T}$. High correlation coefficient $\left(R^{2}=0.9178\right)$ obtained in this study indicated the applicable of this isotherm in describing the equilibrium data.

\subsection{Adsorption kinetics studies}

Fig. 9 shows the removal efficiency of AC2 for 2,4-DCP. The equilibrium time for the adsorption of 2,4-DCP on sample AC2 is $180 \mathrm{~min}$. Three kinetic models, pseudo first-order, pseudo second-order and intraparticle diffusion were used to analyzed the kinetic and dynamic of adsorption process of 2,4-DCP on AC2.

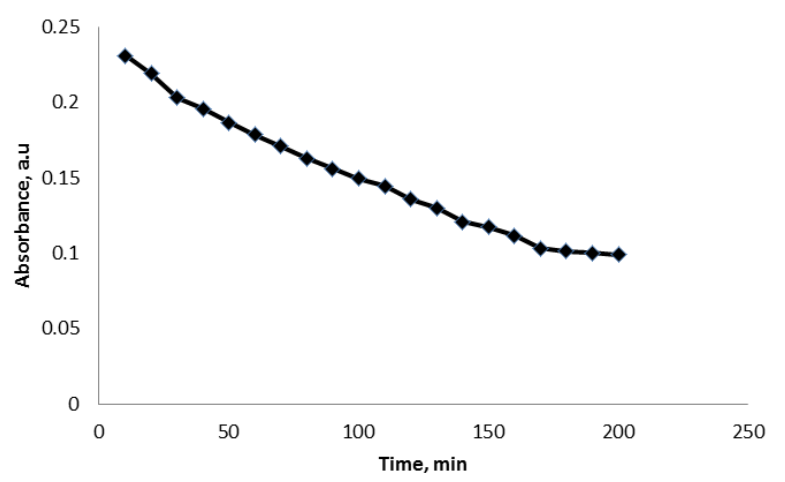

Fig. 9. Removal efficiency of AC2 for 2,4-DCP

The linear form of pseudo first-order equation can be expresses as

$\log \left(q_{\mathrm{e}}-q_{\mathrm{t}}\right)=\log q_{\mathrm{e}}-\frac{k_{\mathrm{l}} t}{2.303}$ where $q_{\mathrm{e}}$ and $q_{\mathrm{t}}$ refer to the amount of 2,4-DCP adsorbed $\left(\mathrm{mg} \mathrm{g}^{-1}\right)$ at equilibrium and at time $t$, respectively, and $k_{1}$, is the equilibrium rate constant of pseudo first-order sorption $\left(\mathrm{min}^{-1}\right)$. The values $\log \left(q_{\mathrm{e}}-q_{\mathrm{t}}\right)$ of for 2,4-DCP were calculated and plotted against time as Fig. 10 a illustrates. The value of $k_{1}$ was calculated from the slope of this plot and listed in Table 4.

The linear form of pseudo-second-order equation can be expresses as:

$$
\frac{t}{q_{\mathrm{t}}}=\frac{1}{k_{2} q_{\mathrm{e}}^{2}}+\frac{t}{q_{\mathrm{e}}}
$$

where $k_{2}$ is the rate constant of pseudo-second-order adsorption (g/mg min).

Fig. $10 \mathrm{~b}$ showed the linearized form of the pseudosecond order model for the adsorption of 2,4-DCP onto AC2. The value of $k_{2}$ was calculated from the slope of this plot and listed in Table 4. From Fig. 10 a, it was observed that the sorption data could be represented by the model only for the initial period and thereafter it deviates from the theory. The applicability of pseudo-first-order model only for the initial period of the sorption process suggests that it is inappropriate to use this kinetic model in representing the sorption kinetics of 2,4-DCP for the entire sorption period. Besides, the correlation coefficient, $\mathrm{R}^{2}$ was relatively small, at 0.7819 .
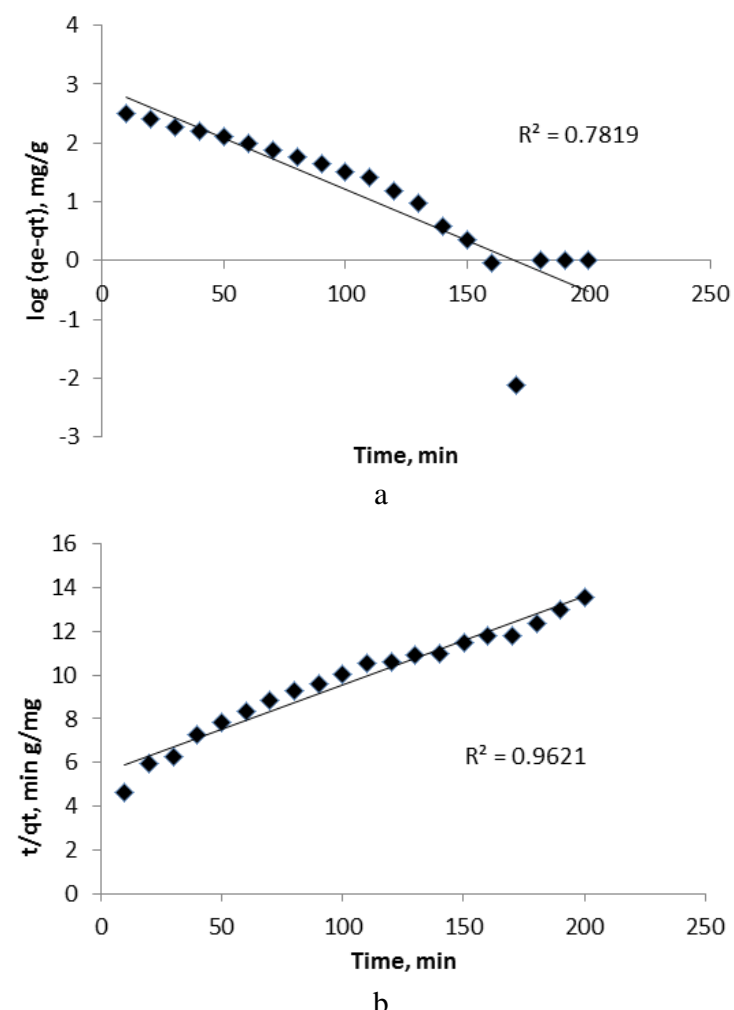

Fig. 10. 2,4-DCP adsorption on AC2: a-pseudo first-order model; $b$ - pseudo second order model

Table 4. Kinetic parameters for the removal of 2,4-DCP by AC

\begin{tabular}{|c|c|c|c|c|}
\hline $\begin{array}{c}\text { Initial 2,4-DCP } \\
\text { concentration, } \\
\mathrm{mg} \mathrm{L}^{-1}\end{array}$ & \multicolumn{2}{|c|}{ Pseudo-first-order } & \multicolumn{2}{c|}{ Pseudo-second-order } \\
\cline { 2 - 5 } & $k_{1}$ & $R^{2}$ & $k_{2}$ & $R^{2}$ \\
\hline 20 & 0.0401 & 0.7819 & 0.0003 & 0.9621 \\
\hline
\end{tabular}


It can be seen from the Table 4 that $R^{2}$ values for pseudo second-order is relatively high as compared to that of the pseudo-first-order equation, indicating the applicability of pseudo-second-order kinetic model in describing the adsorption system. The high $R^{2}$ value also implies that the sorption data can be well represented by pseudo second-order kinetics and thus supports the assumption behind the model that sorption is controlled by chemisorption.

\subsection{Intraparticle diffusion model}

Intraparticle diffusion model based on the theory proposed by Weber and Morris was used to analyze the mechanism of diffusion. The equation is given by:

$q_{\mathrm{t}}=k_{\mathrm{p}} t^{\frac{1}{2}}+c$

where $k_{p}$ is the intraparticle diffusion rate constant $\left(\mathrm{mg} \mathrm{g}^{-1} \min ^{1 / 2}\right.$ ) and $c$ is the constant related to the thickness of the boundary layer. Fig. 11 illustrates the plot of $q_{t}$ versus $t^{0.5}$ for the adsorption of 2,4-DCP on AC2.

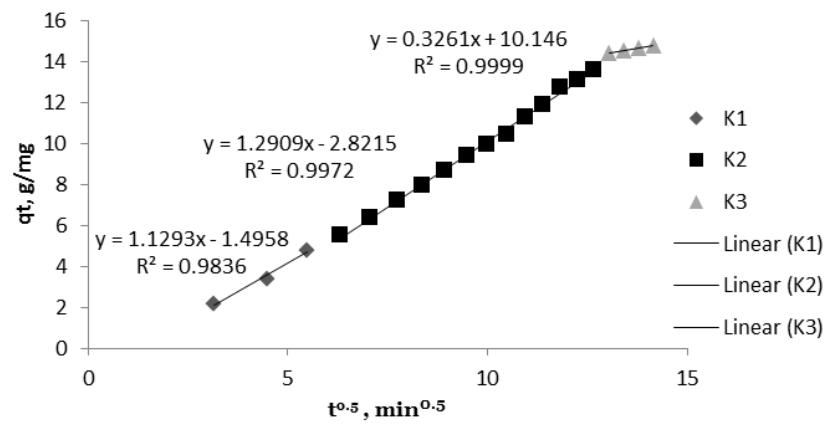

Fig. 11. Intraparticle diffusion kinetic plot of $\mathrm{AC} 2$ for the adsorption of 2,4-DCP

As can be seen in Fig. 11, the plot of $q_{\mathrm{t}}$ versus $t^{0.5}$ exhibits multi-linearity, indicating the adsorption process is controlled by more than one mechanism. The presence of region $\mathrm{K} 1, \mathrm{~K} 2$ and $\mathrm{K} 3$ shows that the adsorption process consists of 3 steps. The first step of the adsorption process is external surface adsorption which is represented by the region K1. 2,4-DCP would first occupy the active sites in the micropores region despite encounters with large pores during diffusion process from bulk solution phase into AC. This is because there is a critical pore width that determines the size of pores for retaining the adsorbate molecules. The critical pore width is approximately 1.3 to 1.8 times the width of adsorbate molecules. For 2,4-DCP which is around $0.7 \mathrm{~nm}$, the critical pore width will be in the range of $0.91 \mathrm{~nm}$ to $1.26 \mathrm{~nm}$ which is the micropore region of carbon. A high intraparticle diffusion rate constant in the first step of adsorption indicates a fast initial uptake of 2,4-DCP by prepared carbon. This is probably due to the large concentration gradient and availability of abundant surface sites on carbon at the beginning of adsorption process [35]. The second step of adsorption process is particle diffusion, where adsorbate ions travel within the pores of adsorbent except for a small amount of adsorption that occurs on the exterior surface of adsorbent [28]. In theory, the second step is a gradual adsorption step as the available surface sites in micropore region reduce owing to the blockage of pores by 2,4-DCP molecules [35]. However, the second step of adsorption process in this study is faster than the first step of adsorption. This is probably due to the low affinity of adsorbent for adsorbate at the initial stage which minimizes the effect of pore blockage and causes the transport of the adsorbate more efficient. Intraparticle diffusion starts to slow down at the third step of adsorption process as a result of low 2,4-DCP concentration left in the solution. Region 3 is the final equilibrium stage and thus has the lowest rate constant. Table 5 represents the intraparticle diffusion constants and correlation coefficients for each region of adsorption process. Table 6 shows the literature values of previous studies of AC using $\mathrm{ZnCl}_{2}$ as activating agent for comparison.

Table 5. Intraparticle diffusion constants and correlation coefficients for each region of adsorption process

\begin{tabular}{|c|c|c|}
\hline Region & $k_{\mathrm{p}} / \mathrm{mg} \mathrm{g}^{-1} \mathrm{~min}^{-0.5}$ & $R^{2}$ \\
\hline $\mathrm{K} 1$ & 1.1293 & 0.9836 \\
\hline $\mathrm{K} 2$ & 1.2909 & 0.9972 \\
\hline $\mathrm{K} 3$ & 0.3261 & 0.9999 \\
\hline
\end{tabular}

Table 6. Previous studies on $\mathrm{AC}$ using $\mathrm{ZnCl}_{2}$ as activating agent

\begin{tabular}{|c|c|c|}
\hline Precursor & Experiment Condition & Quality of the product \\
\hline Coconut shell & $\begin{array}{l}\text { Activation time }=2 \mathrm{~h}, \text { activation temperature }=200- \\
700^{\circ} \mathrm{C}, \mathrm{N}_{2} \text { atmosphere }\end{array}$ & $\begin{array}{l}\text { Chemical activation produces highly active carbon, which presents } \\
\text { a wider, meso- and macro-porosity. The optimum values for } \\
\text { activation time and impregnation ratio in producing activated } \\
\text { charcoal were } 50 \mathrm{~min} \text { and } 40 \% \text {, respectively, at } 600^{\circ} \mathrm{C} \text {. }\end{array}$ \\
\hline Coffee husks & $\begin{array}{l}\text { erric chloride }\left(\mathrm{FeCl}_{3}\right) \text { and } \mathrm{ZnCl}_{2} \text { as activating agents, } \\
\text { npregnation ratio }=1: 1 \text {, at } 550{ }^{\circ} \mathrm{C} \text { for } 3 \mathrm{~h}, \mathrm{~N}_{2} \\
\text { mosphere }\end{array}$ & $\begin{array}{l}\text { BET surface area } 900 \mathrm{~m}^{2} \mathrm{~g}^{-1} \text {. The activation with } \mathrm{FeCl}_{3} \text { produces } \\
\text { smaller pores compared to the activation with } \mathrm{ZnCl}_{2} \text {. Adsorption } \\
\text { capacity (phenol) }=167 \mathrm{mg} \mathrm{g}^{-1}\end{array}$ \\
\hline Walnut shells & $\begin{array}{l}\text { Activation temperature }=350-600^{\circ} \mathrm{C} \text {, activation time } \\
=60 \text { min, impregnation ratio }=1.0-2.0, \text { vacuum } \\
\text { condition }\end{array}$ & $\begin{array}{l}\text { The optimum activated carbon obtained with system pressure of } \\
30 \mathrm{kPa} \text {, activation temperature of } 450{ }^{\circ} \mathrm{C} \text {, and impregnation ratio of } \\
2.0 \mathrm{has} \text { a BET surface area of } 1800 \mathrm{~m}^{2} \mathrm{~g}^{-1} \text { and total pore volume of } \\
1.176 \mathrm{~cm}^{3} \mathrm{~g}^{-1} \text {. }\end{array}$ \\
\hline Sour Cherry Stones & $\begin{array}{l}\text { Impregnation ratio }=1: 1 \text { to } 4: 1, \text { activation temperature } \\
=500-900{ }^{\circ} \mathrm{C}, \mathrm{N}_{2} \text { atmosphere }\end{array}$ & $\begin{array}{l}\text { BET surface area }=1704 \mathrm{~m}^{2} \mathrm{~g}^{-1}, \text { pore } \\
\begin{array}{l}\text { volume }=1.566 \mathrm{~cm}^{3} \mathrm{~g}^{-1} \text {, } \\
\text { Optimum conditions: activation } \\
\text { impregnation ratio }=3: 1\end{array} \text { temperature }=7000^{\circ} \mathrm{C} \text {, }\end{array}$ \\
\hline $\begin{array}{l}\text { Pine sawdust (PS), } \\
\text { rose seed (RS), } \\
\text { cornel seed (CS) }\end{array}$ & $\begin{array}{l}\text { Carbonization temperature }=300-800^{\circ} \mathrm{C}, \\
\text { carbonization time }=1 \mathrm{~h}, \text { impregnation ratio }=0.5- \\
2.0 \text {, impregnation time }=1-3 \mathrm{~h}, \mathrm{~N}_{2} \text { atmosphere }\end{array}$ & $\begin{array}{l}\text { Optimum conditions: carbonization temperature }=400-500{ }^{\circ} \mathrm{C} \text {, } \\
\text { impregnation ratio }=1.5, \text { impregnation time }=1-2 \mathrm{~h} \text {, surface area } \\
=1825 \mathrm{~m}^{2} \mathrm{~g}^{-1}(\mathrm{PS})=1265 \mathrm{~m}^{2} \mathrm{~g}^{-1}(\mathrm{RS})=1355 \mathrm{~m}^{2} \mathrm{~g}^{-1}(\mathrm{CS})\end{array}$ \\
\hline Coconut shell & $\begin{array}{l}\text { Coconut shell was first undergone semi-carbonized at } \\
300^{\circ} \mathrm{C} \text { for } 1 \text { hour followed by chemical activation at } \\
500{ }^{\circ} \mathrm{C} \text { for } 2 \text { hours. Impregnation ratio = } 1: 1 \text { to } 5: 1 \\
\text { according to the } \mathrm{ZnCl}_{2} \text { : chars ratio }(\mathrm{w} / \mathrm{w})\end{array}$ & $\begin{array}{l}\text { Langmuir surface area }=1482 \mathrm{~m}^{2} \mathrm{~g}^{-1} \text {; pore volume, } 0.1697 \times 10^{-2} \mathrm{~m}^{3} \\
\mathrm{~g}^{-1} \text {; The } 2,4-\mathrm{DCP} \text { adsorption results fitted best in the Freundlich } \\
\text { isotherm while the adsorption kinetic fitted to the pseudo second- } \\
\text { order model. }\end{array}$ \\
\hline
\end{tabular}




\section{CONCLUSIONS}

This study showed that the preparation of AC from coconut shell using two stages self-generated atmosphere method was feasible. It has been found that the impregnation ratio used in the chemical activation of coconut shell gave a significant effect on the morphological structure, product yield as well as the adsorption capacity of the prepared activated carbons. The maximum Langmuir surface area of the best produced AC2 was found to be $1482 \mathrm{~m}^{2} \mathrm{~g}^{-1}$. Adsorption of 2.4-DCP was found to increase with an increase in initial concentration and adsorbent dosage while acidic $\mathrm{pH}$ was more favourable for the adsorption of 2.4-DCP. The equilibrium between the adsorbate in the solution and the adsorbent surface was achieved in $180 \mathrm{~min}$. Langmuir, Freundlich and Temkin isotherm models were used to describe the adsorption process. The Langmuir equation was found to be inappropriate for the experimental results. The Freundlich isotherm model was found to be more suitable than Langmuir isotherm model in describing the sorption process as indicated by the high correlation coefficient. Pseudo-first-order, pseudo-second-order and intraparticle models were used to analyzed the kinetic and dynamic of the adsorption process. The kinetic data can be better explained by the pseudo-second-order model as compared to pseudo-first-order model, indicating the adsorption process was controlled by chemisorption. The kinetic study also reveals that the adsorption process follows external diffusion and intraparticle diffusion. As most chlorinated phenol based industrial wastewater are generated by factories situated in rural areas near large rivers in Sabah (Malaysia), this treatment method offers affected villages a localized method to treat their drinking water. After sun-drying, the spent adsorbent can be converted to biomass and use as fuel, thus, eliminating the target pollutant and producing ash for farming.

\section{Acknowledgements}

This work was fully supported by the Centre of Research \& Innovation, Universiti Malaysia Sabah (Grant No.SGK0031-ST-2015), and is gratefully acknowledged.

\section{REFERENCES}

1. Ren, L., Zhang, J., Li, Y., Zhang. C. Preparation and Evaluation of Cattail Fiber-based Activated Carbon for 2, 4dichlorophenol and 2, 4, 6-trichlorophenol Removal Chemical Engineering Journal $168(2)$ 2011: pp. $553-561$.

https://doi.org/10.1016/j.cej.2011.01.021

2. Gonzalez-Serrano, E., Cordero, T., RodriguezMirasol, J., Cotoruelo, L., Rodriguez, J.J. Removal of Water Pollutants with Activated Carbons prepared from $\mathrm{H}_{3} \mathrm{PO}_{4}$ Activation of Lignin from Kraft Black Liquors Water Research 38 (13) 2004: pp. 3043-3050.

3. Jung, M.W., Ahn, K.H., Lee, Y., Kim, K.P., Rhee, J.S., Tae Park, J., Paeng, K.J. Adsorption Characteristics of Phenol and Chlorophenols on Granular Activated Carbons (GAC) Microchemical Journal $70(2)$ 2001: pp. $123-131$. https://doi.org/10.1016/S0026-265X(01)00109-6
4. Moreno-Castilla, C. Adsorption of Organic Molecules from Aqueous Solutions on Carbon Materials Carbon 42 (1) 2004: pp. 83-94.

5. Anisuzzaman, S.M., Joseph, C.G., Daud, W.M.A.W., Krishnaiah, D., Ho, S.Y. Preparation and Characterization of Activated Carbon from Typha Orientalis Leaves International Journal of Industrial Chemistry 6(1) 2015: pp. 9-21.

6. Anisuzzaman, S.M., Joseph, C.G., Krishnaiah, D., Bono, A., Ooi, L.C. Parametric and Adsorption Kinetic Studies of Methylene Blue removal from simulated Textile Water using Durian (Durio Zibethinus Murray) Skin Water Science and Technology 72 (6) 2015: pp. 896-907. https://doi.org/10.2166/wst.2015.247

7. Joseph, C.G., Bono, A., Anisuzzaman, S.M., Krishnaiah, D. Application of Soot in the removal of 2,5dichlorophenol in Aqueous Medium Journal of Applied Sciences 14 (23) 2014: pp. $3182-3191$.

8. Krishnaiah, D., Anisuzzaman, S.M., Bono, A., Sarbatly, R. Adsorption of 2,4,6-trichlorophenol (TCP) onto Activated Carbon Journal of King Saud UniversityScience 25 (3) 2013: pp. 251-255.

9. Prauchner, M.J., Rodríguez-Reinoso, F. Chemical versus Physical Activation of Coconut Shell: A Comparative Study MicroporousMesoporous Materials 152 2012: pp. $163-171$.

https://doi.org/10.1016/j.micromeso.2011.11.040

10. Hesas, R.H., Arami-Niya, A., Daud, W.M.A.W., Sahu, J.N. Comparison of Oil Palm Shell-based Activated Carbons produced by Microwave and Conventional Heating Methods using Zinc Chloride Activation Journal Analytical and Applied Pyrolysis 104 2013: pp. 176-184. https://doi.org/10.1016/j.jaap.2013.08.006

11. Hayashi, J., Kazehaya, A., Muroyama, K., Watkinson, A.P. Preparation of Activated Carbon from Lignin by Chemical Activation Carbon 38 (13) 2000: pp. $1873-1878$.

12. Song, C.W., Wu, S.H., Cheng, M.R., Tao, P., Shao, M.H., Gao, G.R. Adsorption Studies of Coconut Shell Carbons prepared by $\mathrm{KOH}$ Activation for Removal of Lead (II) from Aqueous Solutions Sustainability 6(1) 2014: pp. 86-98.

13. Lillo-Ródenas, M.A., Juan-Juan, J., Cazorla-Amoros, D., Linares-Solano, A. About Reactions occurring during Chemical Activation with Hydroxides Carbon $42(7)$ 2004: pp. 1371-1375.

14. Yang, J., Qiu, K. Preparation of Activated Carbons from Walnut Shells via Vacuum Chemical Activation and their Application for Methylene Blue Removal Chemical Engineering Journal 165 (1) 2010: pp. 209-217.

15. Kennedy, L.J., Vijaya, J.J., Kayalvizhi, K., Sekaran, G. Adsorption of Phenol from Aqueous Solutions Using Mesoporous Carbon Prepared by Two-Stage Process Chemical Engineering Journal 132 (1) 2007: pp. 279-287. https://doi.org/10.1016/j.cej.2007.01.009

16. Uysal, T., Duman, G., Onal, Y., Yasa, I., Yanik, J. Production of Activated Carbon and Fungicidal Oil from Peach Stone by Two-Stage Process Journal Analytical and Applied Pyrolysis 108 2014: pp. 47-55. https://doi.org/10.1016/j.jaap.2014.05.017

17. Arami-Niya, A., Daud, W.M.A.W., Mjalli, F.S. Using Granular Activated Carbon prepared from Oil Palm Shell by $\mathrm{ZnCl}_{2}$ and Physical Activation for Methane Adsorption Journal Analytical and Applied Pyrolysis 89 (2) 2010: pp. $197-203$. 
18. Abechi, S.E., Gimba, C.E., Uzairu, A., Dallatu, Y.A. Preparation and Characterization of Activated Carbon from Palm Kernel Shell by Chemical Activation Research Journal of Chemical Sciences 3 2013: pp. 54-61.

19. Oliveira, L.C.A., $\quad$ Pereira, E., Guimaraes, I.R., Vallone, A., Pereira, M., Mesquita, J.P., Sapag, K. Preparation of Activated Carbons from Coffee Husks utilizing $\mathrm{FeCl}_{3}$ and $\mathrm{ZnCl}_{2}$ as Activating Agents Journal of Hazardous Material 165 (1) 2009: pp. 87-94.

20. Ucar, S., Erdem, M., Tay, T., Karagóz, S. Preparation and Characterization of Activated Carbon Produced from Pomegranate Seeds by $\mathrm{ZnCl}_{2}$ activation Applied Surface Science 255 (21) 2009: pp. 8890-8896. https://doi.org/10.1016/j.apsusc.2009.06.080

21. Anisuzzaman, S.M., Joseph, C.G., Taufiq-Yap, Y.H., Krishnaiah, D., Tay, V.V. Modification of Commercial Activated Carbon for the Removal of 2,4-dichlorophenol from Simulated Wastewater Journal of King Saud University-Science 27 (4) 2015: pp. 318-330.

22. Hamdaoui, O., Naffrechoux, E. Modeling of Adsorption Isotherms of Phenol and Chlorophenols onto Granular Activated Carbon: Part I. Two-Parameter Models and Equations allowing determination of Thermodynamic Parameters Journal Hazardous Materials 147 (1) 2007: pp. $381-394$.

23. Shaarani, F.W., Hameed, B.H. Batch Adsorption of 2, 4dichlorophenol onto Activated Carbon derived from Agricultural Waste Desalination 255 (1) 2010: pp. 159-164.

24. Khalili, N.R., Campbell, M., Sandi, G., Golaś, J. Production of Micro- and Mesoporous Activated Carbon From Paper Mill Sludge: I. Effect of Zinc Chloride activation Carbon 38 (14) 2000: pp. 1905-1915. https://doi.org/10.1016/S0008-6223(00)00043-9

25. Ahmedna, M., Marshall, W.E., Rao, R.M. Production of Granular Activated Carbons from select Agricultural byproducts and Evaluation of their Physical, Chemical and Adsorption Properties Bioresource Technology 71 (2) 2000: pp. $113-123$. https://doi.org/10.1016/S0960-8524(99)00070-X

26. Angin, D. Production and Characterization of Activated Carbon from Sour Cherry Stones by Zinc Chloride Fuel 115 2014: pp. 804-811.
27. Cazetta, A.L., Vargas, A.M.M., Nogami, E.M. Kunita, M.H., Guilherme, M.R., Martins, A.C., Silva, T.L., Moraes, J.C.G., Almeida, V.C. NaOHActivated Carbon of High Surface Area Produced from Coconut Shell: Kinetics and Equilibrium Studies from the Methylene Blue Adsorption Chemical Engineering Journal 174 (1) 2011: pp. 117-125.

28. Hameed, B.H., Tan, I.A.W., Ahmad, A.L. Adsorption Isotherm, Kinetic Modeling and Mechanism of 2, 4, 6trichlorophenol on Coconut Husk-based Activated Carbon Chemical Engineering Journal 144 (2) 2008: pp. 235-244.

29. Hameed, B.H. Evaluation of Papaya Seeds as a Novel Nonconventional Low-cost Adsorbent for removal of Methylene Blue Journal of Hazardous Materials 162 (2) 2009: pp. 939-944.

30. Mozammel, H.M., Masahiro, O., Bhattacharya, S.C. Activated Charcoal from Coconut Shell using $\mathrm{ZnCl}_{2}$ Activation Biomass and Bioenergy 22 (5) 2002: pp. 397-400. https://doi.org/10.1016/S0961-9534(02)00015-6

31. Acikyildiz, M., Gürses, A., Karaca, S. Preparation and Characterization of Activated Carbon from Plant Wastes with Chemical Activation Microporous and Mesoporous Materials 198 2014: pp. 45-49.

32. Radhika, M., Palanivelu, K. Adsorptive removal of Chlorophenols from Aqueous Solution by Low Cost Adsorbent-Kinetics and Isotherm Analysis Journal of Hazardous Materials 138 (1) 2006: pp. 116-124.

33. Sathishkumar, M., Binupriya, A.R., Kavitha, D., Selvakumar, R., Jayabalan, R., Choi, J.G., Yun, S.E. Adsorption Potential of Maize Cob Carbon for 2,4-dichlorophenol removal from Aqueous Solutions: Equilibrium, Kinetics and Thermodynamics Modeling Chemical Engineering Journal 147 (2) 2009: pp. $265-271$.

34. Maarof, H.I., Hameed, B.H., Ahmad, A.L. Adsorption Isotherms for Phenol onto Activated Carbon ASEAN Journal of Chemical Engineering 4 (1) 2004: pp. 70 - 76.

35. Sze, M.F.F., McKay, G. An Adsorption Diffusion Model for removal of Para-chlorophenol by Activated Carbon derived from Bituminous Coal Environmental Pollution 158 (5) 2010: pp. $1669-1674$. 